\title{
Por EL DERECHO A LA IGUALDAD DE GÉNERO: TUTELA PROCESAL CIVIL"
}

Teresa Armenta Deu***

\section{RESUMEN}

A partir de una breve introducción de la igualdad entre mujeres y hombres por el legislador y en la aplicación de la ley, el trabajo se dirige rectamente al ámbito de la tutela procesal civil del derecho a la igualdad por razón de sexo en el ordenamiento español. Dicha tutela abarca tres mecanismos distintos: el proceso ordinario para la tutela de derechos fundamentales y sus especialidades, la tutela dentro del

Fecha Recibido: marzo 12 de 2014 - Fecha Aceptado: mayo 30 de 2014

* Este trabajo tuvo su origen en un curso de formación de jueces y magistrados del Consejo General del Poder Judicial. Se publicó inicialmente en la Revista Jurídica de Cataluña, número 1, 2010, pp. 39-61.

*: Doctora por la Universidad de Barcelona, es actualmente, Catedrática de derecho procesal de la Universidad de Girona (UdG) (España), Vocal de la Comisión General de Codificación y Directora del Centro de Estudios Avanzados del Proceso y de la Justicia (CEAPJ). Becaria Humboldt, ha realizado frecuentes estancias en la Universidad de Múnich (Alemania) y la Northwestern University (Chicago) y colabora habitualmente con las Universidades de Milán, Roma; la UNAM (México) y la UBA (Buenos Aires), y otras varias en Perú y Ecuador, participando en Congresos, Seminarios y dirigiendo trabajos de investigación. Participa habitualmente en Congresos como ponente y en cursos de "Formación continuada" para jueces, magistrados, fiscales y policía en España, Alemania, México y Argentina. Pertenece a la Asociación Hispano-Alemana de Juristas, a la Asociación Iberoamericana de Derecho Procesal y a la Asociación Internacional de Derecho Procesal. Es miembro del Consejo de Redacción de la Editorial Marcial Pons (España), del Boletín del Ministerio de Justicia, de la Revista Justicia y de la Revista de Derecho Penal (Argentina). Ha escrito más de doce monografías, más de veinte libros en que se escribe parte de la obra, Estudios y más de 30 artículos en revistas españolas y extranjeras. Es autora además de diversos manuales y materiales docentes. 
proceso a través de la nueva formulación de la nulidad de actuaciones, y dos instrumentos procesales específicos incorporados a la Ley de Enjuiciamiento Civil: la legitimación contemplada en la LO 3/2007 para la igualdad efectiva de mujeres y hombres y la regla específica sobre la carga de la prueba que ha modificado la regla general del art. 217,2 y 3 LEC. El trabajo se ofrece una visión resumida aunque suficientemente ilustrativa sobre las tendencias del derecho de la UE en esta materia y su innegable influencia en el marco interno y otros aspectos tan debatidos como la "discriminación positiva", la legitimación colectiva y la protección de los intereses colectivos y difusos o la discutida cuestión sobre el desplazamiento de la carga de la prueba.

Palabras clave: Igualdad por razón de género, discriminación positiva, tutela derechos fundamentales, nulidad de actuaciones, test de igualdad, carga de la prueba y su desplazamiento.

\section{Abstract}

Starting from a brief introduction of equality between men and women by the legislator and in the application of the law, the project is directly directed to the field of the civil procedural protection of law to sex equality in the Spanish legal system. The above mentioned protection covers three distinct mechanisms: the ordinary process for the protection of fundamental rights and their specializations, the protection within the process through the new formulation of the nullity of proceedings, and two specific procedural instruments incorporated to the Spanish Law of Civil Procedure: the contemplated legitimization of the LO 3/2007 for the effective equality of women and men and the specific rule on the burden of proof which has modified the general rule of art. 217, 2 and 3 LEC. The project offers a summarized vision, although sufficiently illustrative on the tendencies of UE law in this subject and its undeniable influence on the internal frame and other debatable aspects such as "positive discrimination", collective legitimization and the protection of the collective and common interests or the controversial question of the shift of the burden of proof.

Key words: Sex equality, positive discrimination, protection of fundamental rights, nullity of proceedings, equality test, burden of persuasion, reversal of the burden of proof, presumptions. 


\section{INTRODUCCIÓN}

El principio de igualdad ha sido uno de los postulados básicos del ordenamiento. Y la igualdad de todos los ciudadanos ante los derechos y deberes previstos en la ley una de sus fórmulas clásicas.

Esta configuración de la igualdad de todos los ciudadanos ante los derechos y deberes previstos por el ordenamiento acarrea dos efectos: no afirma que todos sean iguales sino que deben ser tratados igual, en tanto, por otra parte, limita su operatividad a la esfera jurídica, a los criterios de asignación de derechos y deberes, y no necesariamente a las esfera social y económica, más allá de lo que incidan las normas en estas realidades.

Desde este punto de vista, para los tribunales, el principio de igualdad ante la ley resulta relevante sólo en cuanto exigencia de igualdad en la aplicación de la ley, o lo que es lo mismo, en cuanto que la ley debe ser aplicada sin distinciones, salvo aquellas que se contemplen por la propia norma (STC 68/1991).

No es ésta la única perspectiva, sin embargo. Con ella convive aquella que examina la exigencia de igualdad frente al legislador, exigiéndole un trato igualitario, o lo que es lo mismo, prohibiendo la discriminación normativa A ella se hará una primera y breve referencia a modo de introducción.

\section{EXIGENCIA DE IGUALDAD POR EL LEGISLADOR (BREVE REFERENCIA)}

Muy resumidamente, el derecho a un trato igualitario en la ley significa que el legislador no puede otorgar un trato diferente a personas que se encuentren en la misma situación (STC 144/1988), lo que equivale a la prohibición de discriminación normativa. Sin poder detenernos ahora en el complejo significado de la igualdad de trato a tenor de los diferentes elementos en juego, baste señalar que a efectos del tema que centra nuestra atención, la ausencia de igualdad de trato por el legislador o lo que es igual la existencia de una discriminación normativa corresponde a una opción de política legislativa que se encuentra limitada por el fundamento y justificación de su adopción, lo que no impide en modo alguno la adopción de "acciones positivas", como veremos ${ }^{1}$.

Sobre las complejidad de este derecho (el significado de la igualdad de trato; las diferenciaciones normativas prohibidas y las diferenciaciones normativas irrazonables, así como sobre las acciones positivas, Cfr. DIEZ-PICAZO-GIMENEZ, L. M. Sistema de Derechos fundamentales, Thomson. Civitas; Madrid, 2003, pp. 177-186. 
Desde el punto de vista de un trato diverso, se prohíben diferencias normativas irrazonables, arbitrarias o injustificadas, lo que equivale a que en caso de tener que recurrir a tal situación deberá efectuarse un "juicio de razonabilidad", como criterio que delimita la discriminación aceptable o inaceptable, es decir, un test de aplicación compleja, que se ve acompañado de otros criterios de diferenciación concretos, como la raza, el sexo, la religión, etc. Este criterio referido en nuestro caso concreto al sexo debe informar los diferentes preceptos que analizaremos seguidamente.

Las acciones positivas, por su parte, traducción del original anglosajón affirmative action, hacen referencia al trato formalmente desigual de una situación cuya finalidad es avanzar hacia la igualdad de grupos tradicionalmente preteridos: las mujeres, en nuestro caso.

Con la meta de igualar las oportunidades, se acude a determinados criterios discriminatorios (cuotas, puntos adicionales) para favorecer la igualdad en el punto de partida a la hora de beneficiarse de algo que siendo escaso no alcanzará a todos. Admitidas de forma desigual, resultan en todo caso una opción que debe acometerse teniendo siempre presente los siguientes criterios: a) exclusión del puro automatismo; b) temporalidad; y c) proporcionalidad. Sobre ellas volveremos al analizar la nueva configuración de la carga de la prueba en los arts. 13 LOIEMH y 217, 5 LEC.

\section{IGUALDAD DE APLICACIÓN DE LA LEY}

A falta de sumisión al precedente, la jurisprudencia continental europea hace prevalecer la independencia judicial sobre la uniformidad de las resoluciones, de manera que los tribunales no están vinculados al criterio de otros tribunales ni al suyo propio. Ahora bien, los eventuales cambios de criterio, en aras a la igualdad de aplicación, deben ser expresos y motivados.

Los sucesivos pasos de la doctrina constitucional a este respecto pueden concatenarse resaltando los siguientes aspectos:

"La regla general de la igualdad ante la ley contenida en el art. $14 \mathrm{CE}$ es asimismo igualdad en la aplicación de la ley, que en el ámbito de la función jurisdiccional no requiere tanto que se produzca siempre la misma interpretación y aplicación de la ley a efectos de los sujetos a los cuales se dirija la resolución...sino que los órganos jurisdiccionales no emitan pronunciamientos arbitrarios o discriminatorios" (STC 63/1984);

"En la aplicación jurisdiccional de la ley puede existir violación del principio de igualdad, cuando un mismo precepto se aplique en casos iguales con notoria desigualdad por motivaciones arbitrarias (no fundadas en razones 
jurídicamente atendibles) o con apoyo de alguna causa de discriminación explícita o genéricamente incluidas en el art. 14 CE” (STC 8/1981, de 30 de marzo).

"Un mismo órgano no puede modificar arbitrariamente el sentido de sus decisiones en casos sustancialmente iguales. Cuando el órgano en cuestión considere que debe apartarse de sus precedentes debe ofrecer para ello un fundamento suficiente y razonable. Cuestión distinta por cierto al problema de la igualdad de la aplicación de la ley cuando ésta no se refiere a un único órgano sino a órganos plurales..." (SSTC 49/1982; 108/1988; o 42/1993, entre otras);

"La legitimación constitucional de la norma, desde la perspectiva del principio general de igualdad, requiere, además de la razonabilidad de la diferenciación (...), que ésta no conduzca a consecuencias desproporcionadas que deparen que dicha razonable diferencia resulte inaceptable desde la perspectiva constitucional. Este análisis de ausencia de desproporcionalidad tomará en cuenta tanto la razón de la diferencia como la cuantificación de la misma: deberá constatar la diferencia de trato que resulta de la norma cuestionada y relacionarla con la finalidad que persigue... Sólo concurrirá una desproporción constitucionalmente reprochable ex principio de igualdad entre las consecuencias de los supuestos diferenciados, cuando quepa apreciar entre ellos un desequilibrio patente y excesivo o irrazonable (...) a partir de las pautas axiológicas constitucionalmente indiscutibles y de su concreción en la propia actividad legislativa.." (STC 59/2008); finalmente,

Son parámetros para evaluar la posible aplicación discriminatoria de la ley por un mismo órgano jurisdiccional: a) la aportación de una concreta y definida orientación jurisprudencial de la que sean predicables los rasgos de generalidad, continuidad y firmeza; b) la existencia de alteridad en los supuestos contrastados; y c) la identidad del órgano, tanto a nivel de Sala como de Sección (STC 229/2003).

\section{Tutela Judicial Del DeREChO A LA IGUALdAd}

Corresponde examinar seguidamente quésucede antela eventual discriminación, o lo que es lo mismo, de qué mecanismos de acceso a la justicia disponen los ciudadanos para denunciar la discriminación en el proceso civil, ámbito en el centraremos nuestra atención.

Con carácter general, cuando se entienda que al resolver los tribunales se ha discriminado por razón de sexo, se abren dos vías de tutela según la violación del derecho fundamental a la igualdad se produzca una vez finalizado el proceso o en el seno del mismo. 
La eventual violación producida fuera del proceso se tutela a través del cauce procesal del art. 53.2 CE, hoy desarrollada a través del procedimiento declarativo ordinario al que remite el art. 249.1.2 LEC. En tanto, si se produjo en el seno del proceso, se articulará a través de los recursos, ordinarios o extraordinarios, y agotada la vía jurisdiccional ordinaria, recurriendo en amparo ante el Tribunal Constitucional. Efectuaré una referencia somera a ambos instrumentos procesales, atendidas las relativamente recientes modificaciones de sus respectivas regulaciones legales.

\subsection{El proceso ordinario para la tutela de derechos fundamentales y sus especialidades}

Derogadas expresamente las normas procesales especiales en materia de jurisdicción civil de los derechos fundamentales, contenidas en los artículos. 11-15 de la Ley de Protección Jurisdiccional de los Derechos Fundamentales de la Persona ${ }^{2}$, la LEC no regula como proceso especial la tutela de los derechos fundamentales en el ámbito procesal civil.

Por tanto, a efectos del art. 53.2 CE, el proceso ordinario referido en el art. 249.1.2 LEC es ahora el procedimiento previo a la vía del amparo constitucional, una vez cumplidos los restantes requisitos. No obstante su naturaleza ordinaria, se le atribuye el carácter de sumario, interpretando tal término como preferente y rápido ${ }^{3}$.

A ello se une, en atención precisamente a la naturaleza de los derechos en conflicto, las siguientes especialidades:

Su ámbito objetivo de aplicación comprende la tutela de derechos fundamentales a excepción de los relativos a los derechos al honor, a la intimidad, a la propia imagen y el derecho de rectificación (art. 249.1.2 ${ }^{\circ}$ LEC). La tutela del derecho al honor y a la propia imagen se rige por la LO 1/1982, de 5 mayo, constituyendo por tanto un proceso especial; en tanto el derecho de rectificación se sigue a través del juicio verbal en aplicación de la LO 2/1984, de 26 de marzo y del art. 250.1.9 $9^{\circ}$ LC.

La competencia se rige por una norma de carácter imperativo (art. 54.1 LEC), estableciéndose a favor del juez del domicilio del demandado, salvo que no lo tuviera en territorio español, en cuyo supuesto corresponde al juez del lugar en

Ley 62/1978, de 26 de diciembre (DD única 2.3 LEC).

3 Puede leerse el desarrollo de este procedimiento En: ARMENTA DEU, T., Lecciones de Derecho Procesal Civil, 4a ed. Marcial Pons, 2009. 
donde se hubiera producido el hecho que haya vulnerado el derecho de que se trate (la igualdad en nuestro caso) (art. 52.1.6 $6^{\circ} \mathrm{LEC}$ ).

El plazo de presentación de la demanda, a falta de mención alguna específica en la LEC, será de 4 años a tenor de lo señalado en el art. 9.5 Ley 1/1982, de 5 de mayo, de protección civil del derecho al honor, a la intimidad personal y familiar y a la propia imagen.

La intervención del MF es preceptiva, en calidad de defensor de la legalidad (art. 249.1.2 ${ }^{\circ}$ LEC).

Finalmente, constituyen otras especialidades procesales: a) la exclusión de la ejecución provisional, a excepción de los aspectos puramente patrimoniales, como la indemnización que se fije (art. 525.1.1 ${ }^{\circ} \mathrm{LEC}$ ); y b) el acceso al recurso de casación en razón a la materia, por entenderse expresamente como resolución recurrible las sentencias que se dicten para la tutela judicial civil de derechos fundamentales, con exclusión de los del art. 24.2 CE (art. 477.2.1 LEC y D.F $16^{\mathrm{a}}$ LEC).

\subsection{La tutela dentro del proceso, específica mención a la nueva formulación de la nulidad de actuaciones}

El mal llamado incidente de nulidad de actuaciones, que no resulta tal en la medida en que el proceso ha finalizado, lleva constituyendo un auténtico "banco de pruebas" a muchos efectos, y singularmente, para propiciar que los tribunales ordinarios pudieran declarar la nulidad cuando el proceso hubiera finalizado, y siempre que se acreditara haberse producido indefensión. El objetivo no era otro que evitar la proliferación de recursos de amparo, como única vía al alcance del justiciable una vez agotados los recursos y siendo firme la resolución ${ }^{4}$; objetivo que se reconoce paladinamente en la última reforma ${ }^{5}$.

$4 \quad$ La LO 5/1997, de 4 de diciembre modificó el art. 240 LOPJ, objeto de posterior reforma por LO 13/1999, de 14 de mayo. También la LEC de 2000 contemplaba la nulidad en sus arts. 225 a 230, si bien no llegó a entrar en vigor (D. Final 17 $\mathrm{LEC}$ ). Posteriormente, la nueva reforma de la LOPJ por LO 19/2003, de 23 de diciembre otorga nueva configuración legal al art. 241; y finalmente, de momento, la LO 6/2007, de 24 de mayo, de modificación de la LO del Tribunal Constitucional, torna a reformar el art. 241.1.I LOPJ.

5 Exposición de Motivos de la Ley Orgánica 6/2007, de 24 de mayo, por la que se modifica la Ley Orgánica 2/1979, de 3 de octubre, del Tribunal Constitucional: La protección y garantía de los derechos fundamentales no es una tarea única del Tribunal Constitucional, sino que los tribunales ordinarios desempeñan un papel esencial y crucial en ella. Por ello, y con la intención de aumentar las facultades de la jurisdicción ordinaria para la tutela de los derechos fundamentales se modifica el incidente de nulidad de actuaciones del artículo 241.1 de la Ley Orgánica 6/1985, de 1 de julio. De este modo se introduce una configuración del incidente 
Amén de conservar su carácter extraordinario, la nulidad de actuaciones se encamina rectamente a obtener la rescisión de la resolución que pone fin al proceso, declarar la nulidad de todo lo actuado y a reponer el procedimiento en el trámite en que se produjo. En el tema que nos ocupa, la discriminación denunciada.

Con tal objetivo, la petición debe sustentarse en la vulneración del principio de igualdad, o lo que es lo mismo, en la existencia de discriminación en el proceso civil de que se trate. Deberá acreditarse, además: a) la existencia de resolución firme; y b) la imposibilidad de haber efectuado la denuncia antes de poner fin al proceso.

El ámbito objetivo de aplicación del incidente resulta, sin embargo, al menos desde una primera y teórica aproximación, de difícil conjunción en el marco del proceso civil, ya que obteniendo la existencia de discriminación por razón de sexo tutela a través del procedimiento ordinario señalado en el art. 249.1.2 ${ }^{\circ}$ LEC, no parece probable que antes de recurrir al amparo se inste la nulidad por lo mismo que se ha debatido en dicho proceso 6 .

Por otra parte, en la última reforma destacan dos novedades: en primer lugar, la omisión de toda mención a la indefensión y en segundo, lo que la Exposición de Motivos califica de ampliación del ámbito de la nulidad.

Como se ha señalado, la referencia a la ampliación tan sólo adquiere sentido si se entiende que el ámbito del incidente de nulidad alcanza la vulneración judicial durante el proceso del derecho de igualdad, tanto desde el punto de vista material como procesal, y en esta hipótesis, la novedad residiría la extensión al ámbito procesal junto a la desaparición de la alusión a la indefensión y por ende a la necesidad de acreditarla ${ }^{7}$.

Los plazos de interposición del incidente son dos. Uno absoluto de cinco años "desde la notificación de la resolución o sentencia"; y otro relativo de veinte días "desde la notificación de la resolución o, en todo caso, desde que se tuvo conocimiento del defecto causante de indefensión" (rectius: desde que se conoció la vulneración del derecho fundamental).

de nulidad de actuaciones mucho más amplia, porque se permite su solicitud con base en cualquier vulneración de alguno de los derechos fundamentales referidos en el artículo 53.2 de la Constitución en lugar de la alegación de indefensión o incongruencia prevista hasta el momento. Esta ampliación del incidente de nulidad de actuaciones previo al amparo busca otorgar a los tribunales ordinarios el papel de primeros garantes de los derechos fundamentales en nuestro ordenamiento jurídico.

6 MONTERO AROCA, J, Derecho jurisdiccional (Proceso civil), 16 ed., p. 503.

7 Ibídem. 
La competencia corresponde al mismo órgano que dictó la resolución que adquirió firmeza, estando legitimados quienes hubieran sido parte o debieran haberlo sido.

Sobre la presentación del escrito y los documentos que se acompañen se declara o no la admisión a trámite, resolviéndose mediante providencia, que si es de inadmisión no será susceptible de recurso alguno (art. 241.1,III LOPJ; art. 228.1, III LEC).

Si se admite el incidente no se suspende la ejecución. Esta regla puede excepcionarse mediante acuerdo expreso cuando la suspensión hiciera perder la finalidad al incidente.

Una vez admitido, se da traslado a las demás partes para que en el plazo de cinco días formule alegaciones.

El recibimiento y celebración de prueba dependerá de si la discriminación puede constatarse en las mismas actuaciones, sin necesidad de más documentos, o no es así. Sólo en este segundo caso deberá recurrirse al trámite incidental de los arts. 393.3 y 4 LEC, citando a las partes a una comparecencia con arreglo a lo previsto para el juicio verbal, tras lo cual se dictará auto en cinco días.

La resolución, si desestima la solicitud de nulidad, puede incorporar condena en costas al solicitante y una multa por temeridad de entre 90 a 600 euros. Cuando se estime, la declaración de nulidad acarreará reponer lo actuado al momento de la infracción o si ésta se produjo al dictar sentencia, resolver de nuevo.

\section{ASPECTOS PROCESALES CIVILES DE LA LEY DE IGUALDAD}

En su lucha por la igualdad real y efectiva, España sigue la estela marcada por el Derecho de la Unión Europea, uno de cuyos principios generales de inspiración es procurar la igualdad (art. 2 Tratado de la Unión), tanto en su aspecto normativo (Derecho originario y derivado), cuanto al seguir la doctrina sentada por el Tribunal de Justicia de la Comunidad Europea (TEJCA).

La jurisprudencia del TEJCE, y en buena medida de las políticas seguidas por la Unión Europea, pueden dividirse en tres etapas diferenciadas: $1^{\text {a) }}$ Hasta la década de los 90 se aborda la igualdad laboral (St Defrenne); $2^{\text {a) }}$ Se incrementan las acciones positivas de los poderes públicos, adoptando medidas estructurales que incrementen la participación en diferentes actividades sociales (St casos Kalanke, Marshall y Badeck); y $3^{\text {a) }}$ Se acogen políticas de transversalidad inauguradas en la Conferencia de Pekín (1995) hacia la incorporación automática y 
sistemática de los problemas de género a todas las instituciones y políticas de los gobiernos ${ }^{8}$.

Centrándonos en las políticas legislativas, la Ley de Igualdad tiene como objetivo principal incorporar al ordenamiento español las dos últimas Directivas Comunitarias en materia de igualdad de trato: La 2002/73 CE, de reforma de la Directiva 76/207 CEE, relativa a la aplicación del principio de igualdad para el acceso al empleo, la formación y la promoción profesional, y a las condiciones de trabajo; y la Directiva 2004/113/CE sobre aplicación del principio de igualdad de trato en el acceso a bienes y servicios de suministro.

Y más especialmente, en el tema específico que acometemos, deben citarse: La pionera Directiva 97/80/CE del Consejo, de 15 de diciembre de 1997; la Directiva 2006/54/CE del Parlamento Europeo y del Consejo de 5 de julio de 2006 relativa a la aplicación del principio de igualdad de oportunidades e igualdad de trato entre hombres y mujeres en asuntos de empleo y ocupación (refundición), cuyo art. 19.1 se refiere al régimen específico de la carga de la prueba $^{9}$; asimismo, a los arts. 9.2 y 36.2.3 de la Directiva 2000/78, al art. 8.3 de la Directiva 2004/113 y al art. 6.3 de la Directiva 76/207 (reformada por la Directiva 2002/73).

Sin entrar en consideraciones de índole general -por conocidas- baste señalar que el marco de aplicación de la Ley Orgánica 3/2007, de marzo para la igualdad efectiva de mujeres y hombres es multidisciplinar y transversal, al objeto de procurar -según señala la Exposición de Motivos- la proyección del principio de igualdad sobre los diversos ámbitos de la realidad social, cultural y $\operatorname{artística~}^{10}$.

8 Amén de las resoluciones citadas, destacan a tales efectos las sentencias recaídas en los casos Gerste (necesidad de proteger a las mujeres y sus circunstancias especiales (embarazo, lactancia, permisos de maternidad), así como la vida familiar y el desarrollo de su actividad profesional; y desarrollando este último aspecto, las Sentencias de los casos Brown, Hoever y Zachown, Krüger y Hill (la mujer y su especial rol en las relaciones laborales), y Sts Minne, Boyle, Griesmar, Coote y Gillespie -equiparación de exigencias en lo profesional a hombres y mujeres-). Cfr. Informe del Consejo General del Poder Judicial al Anteproyecto de LO de igualdad entre Mujeres y Hombres.

9 En él se recogen los anteriores arts. 4 y 8 de la Directiva 2000/43/CE del Consejo, de 29 de junio de 2000 relativa a la aplicación del principio de igualdad de trato de las personas independientemente de su origen racial o étnico, también en lo referente a la carga de la prueba.

10 La Exposición de Motivos de este texto legal señala expresamente: La mayor novedad de esta Ley radica, con todo, en la prevención de esas conductas discriminatorias y en la previsión de políticas activas para hacer efectivo el principio de igualdad. Tal opción implica necesariamente una proyección del principio de igualdad sobre los diversos ámbitos del 
Aproximándonos definitivamente a los aspectos procesales que centrarán nuestra atención y retomando las líneas generales que enmarcan el respeto a la igualad por razón de sexo, cabe recordar dos extremos altamente ilustrativos para posteriores reflexiones en torno a la legitimación y la prueba ${ }^{11}$.

a) Que no siendo inconstitucional toda desigualdad, sólo la discriminatoria, a la hora de determinar la discriminación debe recurrirse al ya citado "test de igualdad", en virtud del cual puede establecerse cuando el trato diferente es admisible (por proporcionalidad y adecuación de las medidas adoptadas y los fines perseguidos atendidas las circunstancias de tiempo y lugar) y cuando no; circunstancia de singular relevancia en lo relativo a la configuración de la carga probatoria, como veremos; y,

b) Que para detectar estos extremos ayudan, asimismo, la percepción de "categorías sospechosas" o ámbitos de potencial discriminación, aspectos que deberán ser objeto de un singular y pormenorizado examen ${ }^{12}$; y que se aprecian, por ejemplo, en la diferente perspectiva y proyección de la igualdad o las discriminaciones admisibles en el ámbito de las relaciones privadas o en aquellas otras que otorgan derechos frente a los poderes públicos.

\subsection{La legitimación en la LO 3/2007 para la igualdad efectiva de mujeres y hombres}

Si la legitimación ordinaria se basa normalmente en la afirmación de la titularidad del derecho subjetivo, existen otros casos en los que las normas procesales permiten expresamente interponer la pretensión a quien no puede afirmar su titularidad del derecho subjetivo. Estos casos, que deben contemplarse expresamente en la ley, reciben el nombre de legitimación extraordinaria. Esta es la configuración que el legislador ha consagrado en los dos párrafos del art. 10 LEC, refiriéndola a la legitimación ordinaria (art. 10.1 LEC); y a la legitimación por sustitución (art. 10.2 LEC).

ordenamiento de la realidad social, cultural y artística en que pueda generarse o perpetuarse la desigualdad. De ahí la consideración de la dimensión transversal de la igualdad, seña de identidad del moderno derecho antidiscriminatorio, como principio fundamental del presente texto.

11 Sobre los antecedentes puede leerse a DEL POZO PÉREZ, M, ¿Es la tutela procesal de la mujer en la LO de Medidas de protección integral contra la violencia de género un anticipo de la ley de igualdad?, en AAVV. ¿Igualdad para qué?, Comares, 2007. 


\section{A) Legitimación extraordinaria: intereses privados e intereses supra- individuales (colectivos y difusos)}

La legitimación extraordinaria puede contemplar supuestos en que se atiende a la existencia de un interés privado, como sucede en los casos de sustitución procesal ${ }^{13}$. Junto a éstos, la complejidad y la masificación de las relaciones sociales y económicas hacen que una cantidad creciente de actividades afecten, no al individuo, sino a colectividades o grupos o categorías de personas simultáneamente, adquiriendo carácter supraindividual; aparecen, así, los intereses supraindividuales ${ }^{14}$.

La protección de intereses supraindividuales obliga a diferenciar entre intereses colectivos e intereses difusos, e intereses privados e intereses públicos, siguiera sea brevemente y como presupuesto previo a comentar el contenido y extensión del art. 12 LOIEMH, recogido en el art.11 bis LEC ${ }^{15}$.

Los intereses colectivos y difusos, en sentido propio, no presentan diferencias ontológicas, sino que hacen referencia a un mismo fenómeno jurídico, a situaciones paralelas que comportan similares problemas procesales: los derivados de la necesidad de tutela de los intereses supraindividuales.

Con todo, no son fenómenos idénticos. Se detectan, cuando menos, diversidades en torno a dos elementos: a) la extensión y determinación de los sujetos interesados, y b) la vinculación entre los miembros o colectivo interesados.

a) Se habla así de interés colectivo, cuando sea determinable el grupo de personas que se encuentran de forma común y simultánea en una misma situación jurídica con respecto a un bien que todos ellos disfrutan conjunta y solidariamente y respecto del que experimentan una común necesidad; existiendo normalmente una vinculación jurídica de los miembros del grupo con un tercero o entre sí.

13 Art. 507 CC (usufructuario); art. 1111 CC (acción subrogatoria); art. 1552 CC (arrendador); art. 1722 (mandante); y entre otros, art. 1869 CC (acreedor pignoraticio).

14 A este conjunto se refiere, por ejemplo, al art. 11 LEC aludiendo a las asociaciones de consumidores y usuarios y otras entidades legalmente constituidas para la defensa de derechos e intereses de aquéllos.

15 GUTIERREZ DE CABIEDES E HIDALGO DE CAVIEDES, P, "La tutela jurisdiccional de los intereses supraindividuales, colectivos y difusos”, Aranzadi, 1999, p. 199 (passim). También en BUJOSA VADELL, L., "La protección jurisdiccional de los intereses de grupo", J.M. Bosch ed. S.A, Barcelona, 1995. 
b) En tanto se habla de interés difuso, si se trata de una comunidad de sujetos amplia e indeterminada o muy difícilmente determinable. El nexo en este supuesto no será jurídico sino circunstancias fácticas contingentes.

Los intereses supraindividuales, tanto colectivos como difusos, deben diferenciarse asimismo de los derechos individuales plurales, es decir, derechos individuales, privativos e indisponibles por terceros, pero que pueden existir en un número plural y tener un origen fáctico común y un contenido sustantivo homogéneo. Tal sería el caso de la adquisición por una pluralidad de consumidores a un mismo comerciante de un bien que adolece de un mismo defecto de fabricación, en el que los perjudicados son titulares de un derecho subjetivo de acción destinado a disponer de un bien en las condiciones acordadas y a la reparación o resarcimiento de los daños sufridos por cada uno. En este caso, la legitimación "ad causam" corresponde a cada uno (principio dispositivo) y el efecto de la resolución no se extiende pudiendo beneficiar automáticamente a los demás cointeresados que ocupan idéntica situación. Eso no significa, empero, que no sea deseable articular mecanismos semejantes a los articulados en Brasil en el Codigo de Defensa del Cosumidor o a las class action de los EE.UU. de Norteamérica ${ }^{16}$.

\section{B) La legitimación en la LOIEMH}

Con el título Tutela judicial efectiva, el art. 12 de la LO 3/2007, de 22 de marzo (en adelante LOIEHM), para la igualdad efectiva de mujeres y hombres señala:

Cualquier persona podrá recabar de los tribunales la tutela del derecho a la igualdad entre mujeres y hombres, de acuerdo con lo establecido en el art. 53.2 CE, incluso tras la terminación de la relación en la que supuestamente se ha producido la discriminación.

2. La capacidad y legitimación para intervenir en los procesos civiles, sociales y contencioso-administrativos que versen sobre la defensa de este derecho corresponden a las personas físicas y jurídicas con interés legítimo, determinadas en las Leyes reguladoras de estos procesos.

3. La persona acosada será la única legitimada en los litigios sobre acoso sexual y acoso por razón de sexo ${ }^{17}$.

16 Cfr. GUTIERREZ DE CABIEDES e HIDALGO DE CAVIEDES, P., Op. cit. pp. 441 y ss.

17 El art. 184 CP contempla el delito de acoso sexual, en tanto el art. 191 señala que será precisa la denuncia de la persona agraviada, de su representante legal o querella del MF, que actuará ponderando los intereses en presencia. Si la víctima es menor bastará la denuncia del MF. También se menciona la ineficacia del perdón del ofendido para la extinción de la acción penal ni de la responsabilidad de esa clase. 
El precepto, en virtud de la DA Quinta LOIEMH, se ha incorporado a ésta última como art. 11 bis en los siguientes términos:

1. Para la defensa del derecho a la igualdad de trato entre mujeres y hombres, además de los afectados, y siempre con su autorización, estarán también legitimados los sindicatos y las asociaciones legalmente constituidas cuyo fin primordial sea la defensa de la igualdad de trato entre mujeres y hombres, respecto de sus afiliados y asociados, respectivamente.

2. Cuando los afectados sean una pluralidad de personas indeterminada o de difícil determinación, la legitimación para demandar en juicio la defensa de estos intereses difusos corresponderá exclusivamente a los organismos públicos con competencia en la materia, a los sindicatos más representativos y a las asociaciones de ámbito estatal cuyo fin primordial sea la igualdad entre mujeres y hombres, sin perjuicio, si los afectados estuvieran determinados, de su propia legitimación procesal.

3. La persona acosada será la única legitimada en los litigios sobre acoso sexual y acoso por razón de sexo.

En una primera lectura, nos encontramos con el reconocimiento de una legitimación ordinaria a los afectados (art. 11 bis, 1 LEC) y otra legitimación extraordinaria que atiende a los otros dos tipos de intereses nombrados:

1) los intereses colectivos contemplados en el apartado 1 (if), para cuya tutela se legitima a los sindicatos y asociaciones legalmente constituidos, cuyo fin primordial sea la defensa de la igualdad de trato entre mujeres y hombres respecto de sus afiliados y asociados, respectivamente; $\mathrm{y}$

2) los intereses difusos que se recogen en el apartado 2, reconociendo legitimación activa a los organismos públicos con competencia en la materia, a los sindicatos más representativos y a las asociaciones con implantación en todo el territorio del Estado cuyo fin primordial sea la igualdad entre mujeres y hombres ${ }^{18}$.

En uno y otro caso, si bien con diversa intensidad, la intervención de asociaciones y sindicatos, u organismo públicos con competencia en la materia

18 Estos apartados 1 y 2 del art. 11 bis LEC conforman para el ámbito civil la norma de transposición del art. 8.3 de la Directiva 2004/113/CE a cuyo tenor: Los Estados miembros velarán porque las asociaciones, organizaciones o entidades públicas que, de conformidad con los criterios establecidos en su Derecho nacional, tengan un interés legítimo en el cumplimiento de los dispuesto en la presente Directiva, puedan iniciar, en nombre del demandante o en su apoyo, y con su autorización, cualquier procedimiento judicial o administrativos previsto para hacer cumplir las obligaciones que se deriven de la presente Directiva. 
obedece a las dificultades o desventajas de acceso a la jurisdicción de los particulares para promover la defensa de los intereses supraindividuales. Cualquiera de los citados se encontrara en mejor posición, más liberados cuando menos de condicionamientos y obstáculos financieros, sociales o simplemente de tiempo.

1) Los sindicatos y asociaciones legalmente constituidos actuarán respecto de sus afiliados y asociados en un triple plano: a) en defensa de los derechos e intereses propios de la mujer, como finalidad que les es propia (en este caso con un interés público); b) en interés de las mujeres como miembros afiliado o asociados; y c) para la defensa colectiva de la igualdad. Por otra parte, como personas jurídicas que son, gozan de capacidad para ser parte $y$ capacidad procesal, actuando a través de sus órganos estatuarios para suplir su falta de apariencia física.

2) Cuando los afectados sean una pluralidad de personas indeterminadas o de difícil determinación, la legitimación corresponde en exclusiva a los organismos públicos con competencias en ésta materia (Instituto de la Mujer, por ejemplo) a los sindicatos más representativos y a las asociaciones de ámbito estatal cuyo fin primordial sea la igualdad.

La resaltada constricción al marco estatal de sindicatos y asociaciones fue criticada ya en el Informe del CGPJ al Anteproyecto. La razón es la frecuente asunción de competencia en este ámbito por las Comunidades Autónomas, en las que se han publicado sendas Leyes promoviendo la constitución de asociaciones con fines de alcanzar la tan repetida igualdad ${ }^{19}$.

\subsection{La legitimación en los litigios que sigan la vía penal}

Cuando se trate de un proceso penal por acoso sexual o acoso por razón de sexo, el apartado 3 del citado art. 12 LOIEMH reduce la legitimación a la persona acosada.

La restricción de la legitimación se cohonesta con la configuración que el art. 184 CP confiere al delito de acoso sexual, como delito que precisa previa denuncia de la persona agraviada, de su representante legal o del $\mathrm{MF}^{20}$.

19 Así sucede, por ejemplo, en la Comunidad Autónoma de Castilla y León, cuya Ley 1/2003, de igualdad de oportunidades entre mujeres y hombres, establece en su preámbulo como uno de sus objetivos promover la constitución de asociaciones que tengan entres sus fines avanzar en la igualdad de oportunidades entre hombres y mujeres...". La Ley de la Mujer de las Islas Baleares de 2006, que crea el Instituto Balear de la Mujer, el Institut Català de les Dones en Cataluña, y un largo etc.

20 El que solicitare favores de naturaleza sexual, para si o para un tercero, en el ámbito de una relación laboral, docente o de prestación de servicios, continuada o habitual, y con tal 
También concuerda con la inexistencia en el marco del proceso penal de derechos o intereses propios de los justiciables, ni por supuesto de derechos subjetivos públicos a obtener una concreta tutela judicial, circunstancia que niega la legitimación penal como ejercicio de derecho particular alguno.

Parece excluirse, asimismo, la eventualidad de que las asociaciones y organizaciones sociales dedicadas a la tutela de la igualdad de sexo ejerciten la acción popular, a diferencia de lo que se prevé en múltiples leyes autonómicas respecto de los delitos contra la violencia machista, al contemplar la personación como acusador popular de las entidades autonómicas o locales, siempre que las circunstancias lo aconsejen y la víctima o sus familiares lo soliciten o acepten ${ }^{21}$.

Exclusión que se extendería finalmente a los casos en que se ejercitara la acción popular respecto de la acción civil derivada del delito, conforme a la doctrina jurisprudencial, que valora la figura del acusador popular como defensor de intereses generales del conjunto de la sociedad, a diferencia del acusador particular quien actúa en función de intereses propios, y consecuentemente, se le impide ejercitar la acción civil derivada de delito ${ }^{22}$.

\subsection{La carga de la prueba en la Ley de Igualdad}

El art. 13 de la repetida LO 3/2007 (LOIEMH) dispone:

De acuerdo con las leyes procesales, en aquellos procedimientos en los que las alegaciones de la parte actora se fundamenten en actuaciones discriminatorias, por razón de sexo, corresponderá a la persona demandada probar la ausencia de discriminación en las medidas adoptadas y su proporcionalidad.

2. Lo establecido en el apartado anterior no es de aplicación a los procesos penales

Este texto se ha reproducido en el art. 217,5 LEC incorporando un nuevo apartado con el siguiente tenor: A los efectos de lo dispuesto en el párrafo

comportamiento provocare a la víctima una situación objetiva y gravemente intimidatorio, hostil o humillante, será castigado como acosador sexual, con la pena de prisión de 3 a $5 \mathrm{~mm} o$ multa de 6 a $10 \mathrm{~mm}$.

Las penas se agravan si concurren amenazas o prevalen situaciones de superioridad laboral, docente o jerárquica o la víctima resulta especialmente vulnerable por su edad, enfermedad o situación.

21 En Cataluña: Art. 45 L 5/2008, de 24 de abril, del "Derecho de las mujeres a evitar la violencia machista (DOG, n.5123-2.5.2008); en Castilla-León: Art. 10,5 LC y L 2003/144; en Galicia: art. 20 LG 2004/249, Ley para la igualdad de mujeres y hombres.

22 OROMI VALL-LLOVERA, S, El ejercicio de la acción popular, Marcial Pons, 2003, passim. 
anterior, el órgano judicial, a instancia de parte, podrá recabar, si lo estimase útil y pertinente, informe o dictamen de los organismos públicos competentes.

\section{A) La incorporación de normas comunitarias y el referente de la LPL}

La Directiva 97/80/ CE del Consejo, de 15 de diciembre de 1997, fue pionera a los efectos de modificar la tradicional atribución de las reglas de carga de la prueba en esta materia. Su doctrina fue incorporada a la Directiva 2006/54/ CE del Parlamento Europeo y del Consejo, de 5 de julio de 2006, relativa a la aplicación del principio de igualdad de oportunidades e igualdad de trato entre hombres y mujeres.

$\mathrm{Su}$ art. 19 dispone: Los Estados miembros adoptarán con arreglo a sus sistemas judiciales nacionales las medidas necesarias para que, cuando una persona que se considere perjudicada por la no aplicación, en lo que a ella se refiere, del principio de igualdad de trato presente, ante un órgano jurisdiccional $u$ otro órgano competente, hechos que permitan presumir la existencia de discriminación directa o indirecta, corresponde a la parte demandada demostrar que no ha habido vulneración del principio de igualdad de trato.

Por otra parte, se ha destacado el precedente que supuso la normativa laboral, y concretamente, el art. 96 LPL, a cuyo tenor: En aquellos procesos en que de las alegaciones de la parte actora se deduzca la existencia de indicios fundados de discriminación por razón de sexo, origen racial o étnico, religión o convicciones, discapacidad, edad u orientación sexual, corresponderá al demandado la aportación de una justificación objetiva y razonable, suficientemente probada, de las medidas adoptadas y su proporcionalidad ${ }^{23}$.

Adviértase, como después retomaremos, la mención expresa a la necesaria presentación de indicios en ambos preceptos. Antes, una sucinta mención a las reglas generales sobre la carga de la prueba.

\section{B) La carga de la prueba: reglas generales y reglas especiales}

A las partes corresponde la alegación de los hechos que considere apoyan su pretensión, así como la aportación de los datos y medios de prueba necesarios a dicho efecto. Las partes, sin embargo, no tienen la obligación de probar; tienen la carga de la prueba.

23 Texto Refundido aprobado por R.D. Leg. 2/1995, de 7 de abril, reformado por Ley 62/2003, de 30 de diciembre. Similar sentido y precedente se predica del art. 20 de la ley 51/2003, de 2 de diciembre, de igualdad de oportunidades, no discriminación y accesibilidad universal de las personas con discapacidad. Y en el art. 36 de la ley 62/2003, de 30 de diciembre, de medidas fiscales, administrativas y de orden social. 
El concepto de carga responde, como sabemos, al constreñimiento a realizar una conducta (positiva o negativa) que un sujeto procesal experimenta como consecuencia de los inconvenientes o perjuicios que la no realización de tal conducta comporta legalmente o a causa de las ventajas que puede perder por no realizarlas (Goldschdmidt) ${ }^{24}$.

Con arreglo a este concepto, el no ejercicio de un derecho no provoca sanción ni responsabilidad, pero si acarrea, consecuencias desfavorables. En palabras de Rosemberg, la teoría de la carga de la prueba es la teoría de las consecuencias de la falta de prueba ${ }^{25}$.

En el ámbito privado, la determinación de que hechos corresponde probar a cada parte, se realiza con arreglo a criterios razonable y unánimemente admitidos que son los que se recogen en el art. 217 LEC, y cuya aplicación en el tiempo por cierto, no procede de manera inmediata, sino cuando resten dudas una vez examinados los diversos instrumentos procesales para fijar los hechos. Existen criterios generales y criterios especiales.

Los criterios generales para atribuir la carga de la prueba, sobre los que no corresponde entrar ahora, figuran en los apartados 1 a 3 del citado art. 217 LEC y están acompañados de "criterios especiales" recogidos en los apartados 4 a 7 del propio precepto.

Los criterios especiales obedecen a la acomodación a la realidad que proviene de muy diversos factores y cuya previsión legal se consagra en el art. 217,6 LEC, en virtud del cual se aplicarán las reglas generales de distribución de la carga de la prueba, salvo que una disposición legal expresa no distribuya la citada carga con criterios especiales. Unida a esta previsión general es importante tener presente la norma de cierre contenida en el último apartado del propio precepto, facultando al tribunal para tener presente la disponibilidad y facilidad probatoria que corresponde a cada una de las partes del litigio (art. $217,7$ LEC $)^{26}$.

24 GOLDSCHDMIDT, J, Der Prozess als Rechstlage, Berlin, 1925, pp. 335-362.

25 ROSEMBERG, "Die Beweislast. Auf die Grundlage des bürgerlichen Gesetzsbuch und der Zivilprozessordnung”, 5 a ed., Munich, 1965.

26 Concretamente, cuando el art. 217.7 contempla la necesidad de ponderar la facilidad probatoria se está haciendo referencia a un amplio arco de situaciones que precisan acomodar las reglas generales en atención a: tratarse de hechos negativos (que normalmente será más difícil de probar); que deba probar la parte que tiene mayor facilidad con independencia de la naturaleza del hecho afirmado; la parte que dispone de la fuente (como sucede, por ejemplo en casos de responsabilidad médica); o estimar que la mera negativa de los hechos afirmados por el actor, sin ofrecer contradicción alguna, pone de manifiesto un intento de aprovechar la regla general torticeramente. 
Con los criterios especiales el legislador persigue facilitar la prueba a alguna de las partes, como contrapeso a diferentes realidades y en atención a criterios de política legislativa o para allanar las dificultades inherentes al caso, como ocurre precisamente en la lucha contra la discriminación de género, atendiendo a circunstancias específicas como las citadas al final del siguiente párrafo ${ }^{27}$.

Las reglas especiales abarcan un amplio abanico de situaciones que distribuyen la repetida carga siguiendo diversas técnicas que cabe diferenciar en cuatro apartados ${ }^{28}: 1$ ) de modo directo; 2 ) indirectamente ${ }^{29}$; 3 ) invirtiendo la carga de la prueba, y 4) atendiendo a diferentes y variables situaciones, como por ejemplo, la especial dificultad de determinadas pruebas en situaciones de riesgo (daños derivados de la tecnología), por encontrarse los medios probatorios en manos de la parte demandada (responsabilidad médica) o, cuando resulta indeterminable la responsabilidad atribuible a cada uno de los miembros de un grupo (causantes de un incendio, por ejemplo).

La "inversión de la carga de la prueba", resulta un concepto que suele utilizarse para referirse a supuestos en que lo existente en realidad es un desplazamiento de la carga probatoria. Pese a su innegable difusión, alguna de las hipotéticas inversiones resultan en realidad desplazamientos, como ocurre en el caso del art. 217.4 LEC, donde se dispone que el demandante queda exonerado de la carga de probar el hecho constitutivo de la acción y al demandado, sin embargo, se le grave con la carga de la negación del hecho constitutivo. En este y otros casos, más que de una hipotética "inversión de la carga probatoria" debería hablarse de que un litigante queda liberado de la prueba de unos hechos que ordinariamente le corresponderían probar, gravándose paralelamente al litigante contrario.

A diferencia de la citada técnica, las presunciones no invierten la normal carga de la prueba, sino que añaden una carga de la contraprueba, que normalmente no existe. En ellas hay un juicio de probabilidad que enlaza los dos (o más) supuestos de hecho y que fundamenta la norma positiva de presunción, pero no impide la "prueba en contrario". Lo que tampoco impide que no quiera

27 Un análisis pormenorizado en la obra de ORMAZABAL SÁNCHEZ, G, Carga de la prueba y sociedad de riesgo, Marcial Pons, 2005, p. 138.

28 Se sigue la clasificación de MONTERO AROCA, J., La prueba en el proceso civil (5 ${ }^{\mathrm{a}}$ ed.), Thomson-Civitas, 2007, pp. 118-142.

29 Tal sería el caso en opinión de Montero, de la presunción de la buena fe ex art. 434 C.C.; la culpa de la pérdida de la cosa ex art. 1183 CC; la existencia y licitud de la causa de los contratos ex art. 1277 C.C.; o la determinación del centro de interés de una persona jurídica ex art. 10,1, II Ley Concursal. 
considerar indestructible el enlace. Así, la "prueba en contrario" puede ser contraprueba del hecho que se presumiría, pero también puede consistir en demostrar que en el caso concreto no se ha dado el enlace explícito o implícito en la norma, de manera que para enervar el efecto de la presunción el litigante puede contraprobar el hecho presunto, pero también que el enlace no se ha producido $^{30}$.

Nótese finalmente que todo desplazamiento de la carga o aplicación de regla especial comporta una divergencia entre la carga de la alegación o afirmación (carga formal de la prueba) y la carga de la prueba (carga material); es decir, que alguien deber afirmar un hecho para obtener un determinado efecto jurídico, pero, sin embargo, se verá relevado de probarlo porque tal carga se ha desplazado sobre el litigante contrario. A estos efectos jugará de manera relevante el principio de adquisición procesal.

\section{C) La carga de la prueba en la LOIEMH y la LEC ¿inversión de la carga de la prueba; presunción o enjuiciamiento prima facie?}

El art. 217.5 LEC recoge punto por punto el tenor literal del citado art. 13 LOEIMH prescribiendo:

De acuerdo con las leyes procesales, en aquellos procedimientos en los que las alegaciones de la parte actora se fundamenten en actuaciones discriminatorias, por razón de sexo, corresponderá a la persona demandada probar la ausencia de discriminación en las medidas adoptadas y su proporcionalidad.

A los efectos de lo dispuesto en el párrafo anterior, el órgano judicial, a instancia de parte, podrá recabar, si lo estimase útil y pertinente, informe o dictamen de los organismos públicos competentes.

Se omite como es lógico el tercer párrafo del art. 13 LOEIMH, relativo a la inaplicación de esta regla en el marco del proceso penal.

Si recurrimos a una hipótesis de trabajo, para estimar una pretensión en la que se invoque la existencia de discriminación por razón de sexo, el juzgador debería apreciar: la existencia de una diferencia de tratamiento que haya generado un perjuicio a quien demanda ${ }^{31}$; la existencia de una distinción de

30 De la OLIVA SANTOS, Derecho procesal civil (El proceso de declaración, Ceura, $3^{\text {a }}$ ed. p. 428.

31 A tal efecto, cabe recurrir a los conceptos de discriminación que figuran en la propia Directiva: como sucede, por ejemplo en el caso de la igualdad en el empleo y la ocupación, las contenidas en los art.2 que define la discriminación directa "cuando una persona, sea, haya sido o pudiera ser tratada de manera menos favorable; y la indirecta "cuando una disposición, criterio o 
carácter objetivo basada en alguna cualidad ligada a la condición sexual y una relación causal entre la diferencia en el trato generadora del perjuicio.

Así, la configuración legal de la carga de la prueba contenida en el citado art. 217,5 LEC es objeto de interpretaciones diversas: a) constituir una auténtica inversión de la carga de la prueba, b) que se trate de un supuesto de presunción mal redactado; o c) que se asemeje al concepto alemán de Anscheinsbeweis, traducible como enjuiciamiento "prima facie" 32.

a) La primera hermenéutica apela a una atención escrupulosa al tenor literal de los art. 13.1 LOEIMH y 217.5 LEC, señalando que nos encontramos ante una "inversión total, automática e incondicionada" de la prueba, en atención a la cual, la alegación de la condición sexual y la afirmación del trato discriminatorio conducen al reconocimiento de la pretensión, salvo que resultara excluida porque el demandado probara la ausencia de discriminación en las medidas adoptadas o la proporcionalidad de las mismas ${ }^{33}$. En definitiva, una especie de acción positiva de carácter procesal de largo alcance.

Los defensores de la misma, niegan otras hipótesis, y singularmente que se trate de una presunción, argumentando que el precepto no requiere ni hace referencia alguna a la necesidad de acreditar el trato desigual siquiera sea a través de indicios, a diferencia de lo previsto en el art. 9 de la Directiva europea ${ }^{34}$

práctica aparentemente neutros pueda ocasionar una desventaja particular a personas con una religión o convicción, con una discapacidad, de una edad, o con una orientación sexual determinadas, respecto de otras personas, salvo que: (..) pueda justificarse objetivamente con una finalidad legítima y salvo que los medios para la consecución de esta finalidad sean adecuados y necesarios "o que conforme la legislación del país correspondiente deban aplicarse criterios diferenciados....

32 Nótese que en todo caso se produce una disfunción entre la carga formal y carga material de la prueba, ya que el demandante deberá alegar uno o varios hechos (el o los que fundan la discriminación) (carga formal), pero la configuración normativa no le atribuye su carga material sino que la traslada al demandado.

33 CASTRO ARGÜELLES, M. A y ÁlVAREZ ALONSO, D., La igualdad efectiva de mujeres y hombres a partir de la Ley Orgánica 3/2007, de 22 de marzo, Thomson-Civitas, 2007, pp. 210 y ss., citado por Pérez Gil, n. 20. p. 257.

34 Directiva del Consejo 2004/113/CE, de 13 de diciembre de 2004. Y con configuración legal semejante el art. 8 de la también Directiva 2000/43/CE del Consejo, de 29 de junio de 2000, relativa a la aplicación del principio de igualdad de trato de las personas independientemente de su origen racial o étnico, a cuyo tenor: Los Estados miembros adoptarán, con arreglo a su ordenamiento jurídico nacional, las medidas necesarias para garantizar que corresponda a la parte demandada demostrar que no ha habido vulneración del principio de igualdad de trato cuando una persona que se considere perjudicada por la no aplicación, en lo que a ella se refiere, de dicho principio, alegue, ante un tribunal u otro órgano competente, hechos que 
y en los arts. 96 y 179.2 LPL $^{35}$. Y añaden, para reforzar su interpretación, que el apartado 2 del propio art. 9 de la Directiva, se propicia la adopción de medidas que favorezcan más al demandante ${ }^{36}$.

Esta percepción resulta a mi juicio criticable, tanto desde el punto de vista técnico, porque supondría que no se atribuye prácticamente carga de la prueba sobre la existencia de una diferencia de trato generadora o apta para generar un perjuicio para quien reclama, ni siquiera indiciariamente, o de una situación objetiva de desigualdad que encuentre su fundamento en el sexo; y asimismo, por constituir una traslación al ámbito procesal de las acciones positivas que fácilmente choca con el principio de igualdad de armas, y cuyo objetivo podría haberse alcanzado mediante otros instrumentos, como sin ir más lejos el uso adecuado de la previsión legal contenida en el ya citado art. 217,7 LEC que permite valorar la disponibilidad y facilidad probatoria que concurren en cada una de las partes.

b) Una segunda interpretación, aún reconociendo que el tenor literal del precepto sustenta más fácilmente la existencia de una inversión de la carga probatoria, la desecha, defendiendo hallarnos ante una hipótesis normativa cuya finalidad es asignar un valor probatorio preponderante a unos datos; constituyendo, sí, una suerte de acción de discriminación positiva procesal, que no altera empero la estructura ordinaria y se acoge a la técnica de las presunciones para aplicar las reglas contenidas en el art. $217 \mathrm{LEC}^{37}$.

Esta tesis, amén de permitir que pudiera desvirtuarse a través de la prueba, que en el caso concreto no existe el enlace abstracto previsto por la ley entre el hecho indiciario y el hecho presunto, evitaría que la carga de la prueba se escorara más allá de lo razonable.

permitan presumir la existencia de discriminación directa o indirecta. 2. Lo dispuesto en el apartado 1 se entenderá sin perjuicio de que los Estados miembros adopten normas sobre la prueba más favorable a la parte demandante.

35 Cuyo texto se reproduce otra vez para facilitar el contraste: En aquellos procesos en que de las alegaciones de la parte actora se deduzca la existencia de indicios fundados de discriminación por razón de sexo, origen racial o étnico, religión o convicciones, discapacidad, edad u orientación sexual, corresponderá al demandado la aportación de una justificación objetiva y razonable, suficientemente probada, de las medidas adoptadas y su proporcionalidad.

36 "Lo dispuesto en el apartado 1 no impedirá a los Estados miembros adoptar normas sobre admisibilidad de las pruebas que sean más favorables a la parte demandante".

37 PÉREZ GIL, J. "La carga de la prueba en la LO 3/2007, para la igualdad efectiva de mujeres y hombres" en Igualdad de género: una visión jurídica plural. Universidad de Burgos, 2008, pp. 259-260. 
Se apoya, además, en la redacción de la Directiva de la que constituye según la propia Exposición de Motivos transposición, así como del buen resultado de idéntica configuración en el orden laboral a partir del citado art. 96 LPL ${ }^{38}$.

Abundan en esta tesis dos ejemplos de derecho comparado: El parágrafo 22 de la Allgemeines Gleichbehandlungsgesetz (Ley de Igualdad de Trato), de 14 de agosto de $2006^{39}$, a cuyo tenor: si en caso de litigio,una parte acredita indicios que permiten presumir un perjuicio (postergación, agravio...) derivado de alguno de los motivos especificados en el $\$ 1$ de esta ley (sexo, origen étnico, raza, religión o concepción de la vida; discapacitación, edad o identidad sexual), la otra parte queda gravada con la carga de probar que no ha cometido ninguna infracción de las disposiciones dirigidas a proteger frente a dicho perjuicio. Y el art. 40 del Codice delle Pari Oportunita, que en materia laboral, contempla la aportación del actor de elementos de hecho, incluso estadísticos, que resulten idóneos para fundar la presunción de existencia de actos, pactos o comportamientos discriminatorios por razón de $\mathrm{sexo}^{40}$.

Admitiendo esta línea interpretativa, quien alegue la existencia de discriminación por razón de sexo, deberá acreditar indiciariamente la existencia de una diferencia objetiva de trato, generadora o apta para generar un perjuicio para quien reclama, y una situación objetiva de desigualdad que encuentre su fundamento en la diferencia de sexo, a partir de lo cual la norma infiere una relación causal entre la diferencia en el trato generadora del perjuicio.

Si el demandado quiere liberarse de la responsabilidad por el perjuicio originado podrá probar de manera plena la inexistencia de discriminación o, lo que resulta más asequible, enervar la presunción demostrando que en ese caso concreto no existió tal relación de causalidad porque los hechos que constituyen la desigualdad en el trato están amparados por la ley o la proporcionalidad.

c) Una última aproximación cree encontrar en el precepto un supuesto de la llamada "prueba prima facie", traducción del término alemán Anscheinsbeweis. Este tipo de prueba es utilizado por la doctrina alemana para manipular la

38 Así lo interpreta Montero, quien denuncia la imperfecta redacción legal del art. 217,5 LEC señalando que en realidad debería expresar que siempre que el actor haya afirmado y probado hechos de los que pudiera entenderse por lo menos indiciariamente que ha existido trato discriminatorio, corresponde al demandado probar que esos hechos no son discriminatorios. Cfr. MONTERO AROCA, J., La prueba en el proceso civil (5 ${ }^{\mathrm{a}}$ ed.), Thomson-Civitas, 2007. BGB.I S.1897.

40 Decreto Legislativo, 11 aprile 2006 n.198 "Codice delle pari oportunita tra uomo e donna, a norma dell'articolo 6 della legge 28 novembre 2005, n.246” (Gaceta Ufficiale n.125, 31 maggio 2006 -Suplemento Ordinario n.133). 
carga probatoria, asumiendo que en algunos casos, una de las partes tiene sólo la carga de probar la "apariencia" o la "verosimilitud" del hecho que sustenta su pretensión, y no una carga real de probar los hechos. A esa parte le bastará aducir algunos elementos de prueba circunstancial o simplemente demostrar que el hecho corresponde a una "pauta típica" de ese tipo de situaciones. A partir de ahí corresponde a la otra parte, demostrar, que en el caso específico, el hecho fue realmente diferente de lo que aparece prima facie ${ }^{41}$. Utilizado con frecuencia por la doctrina alemana en el marco del derecho de daños, no se encuentra exento de críticas, centradas especialmente por la creación de una "norma sobre el caso" que eventualmente pudiera manipular las cargas probatorias para adoptar decisiones "justas" 4 .

Desechando esta última tesis por los peligros inherentes señalados y porque además la propia redacción legal es susceptible de otras hermenéuticas más plausibles, repasemos para terminar brevemente las dos primeras.

De una parte, avalaría una cierta tensión en la intelección que se ha defendido del art. 217.5 LEC, la referencia al apartado 7 del mismo precepto, que permite que el juez no interprete directamente la inversión de la carga de la prueba, sino que atendiendo precisamente a la facilidad de una de las partes (del demandado, en este caso) pondere que el demandante acredite siquiera indiciariamente la existencia de discriminación.

Conviene tener presente, por otro lado, que recurrir a la inversión de la carga de la prueba en sentido estricto supone una opción legislativa a menudo radical, cuyos peligros se ven aminorados frecuentemente recurriendo a la técnica de las presunciones, que propicia un análisis más modulable en situaciones en las que el legislador claramente quiere beneficiar a una de las partes para compensar las dificultades que originaría una aplicación no alterada de las reglas de la carga de la prueba.

\section{D) Los informes de los organismos competentes}

La referencia legal a estos documentos atiende a eventuales peritajes de organismos como el Instituto de la Mujer o los correspondientes organismos

41 Cfr. ARENS, "Dogmatik und Praxis der Schädensschätzung”, ZZP, 88; (con LÜKE) “Zivilprozessrecht”, München, 1992.

42 La bibliografía alemana es muy extensa, véase por todos MUSIELAK, Grundlage der Beweislast im Zivilprozess, 1975, y del mismo autor (con STADLER) “Grundfragen des Beweisrechts", Manchen, 1984. En castellano, TARUFFO, M. La prueba, Marcial Pons, 2008, p. 154. 
autonómicos que velan por la igualdad en el marco de sus competencias. Recurrir a ellos amplia las máximas de la experiencia del tribunal ${ }^{43}$.

Podrán solicitarse tanto por el demandante como por el demandado, a tenor de los intereses de cada parte. Y paralelamente, el resultado que arrojen podrá beneficiar a la parte contraria a la que los propuso conforme al principio de adquisición procesal y las consecuencias derivadas de la carga formal de la prueba.

Esta referencia, como el uso de la expresión "discriminación en las medidas adoptadas" rememora una vez más situaciones de los particulares frente a actuaciones de los poderes públicos, más que hechos derivados de relaciones entre particulares.

\section{E) La exclusión de la regla de distribución de la carga de la prueba en el proceso penal}

La regla especial de distribución de la carga de la prueba no resulta aplicable al proceso penal (art. 13 LOIEMH), y bien podría añadirse que tampoco la regla general.

En efecto, a diferencia de que lo que sucede en el proceso civil, en el proceso penal, la falta de prueba sobre las circunstancias de actividad y resultado contempladas en el tipo no conducen a idéntico efecto: la función que cumple la distribución de la carga de la prueba en el proceso civil se sustituye en el penal por el principio "in dubio pro reo". A la hora, por tanto, de sopesar los intereses en conflicto (condena del efectivamente culpable o absolución del inocente) prima el segundo, de manera que en la incertidumbre debe absolverse $^{44}$.

43 MARTÍNEZ DIZ, F., "Tutela judicial del derecho de igualdad entre mujeres y hombres y sus repercusiones procesales" en AAVV, Estudios interdisciplinares sobre igualdad y violencia de género, ed. Comares, Granada, 2008, pp. 291-295.

44 En el proceso penal el interés en el efectivo castigo del culpable y en la absolución del inocente no son intereses parciales (de parte) sino comunes, públicos; de aquí que el Ministerio Fiscal deba velar por ellos. Y de ahí, asimismo la imposibilidad de aplicar reglas semejantes de distribución de la carga de la prueba, porque, fundamentalmente, los dos intereses señalados no son parciales; antes bien, tienen un mismo titular. Como señalara GÓMEZ ORBANEJA, en el proceso penal lo que se trata de dilucidar es cuál de aquellos dos intereses debe prevalecer, o dicho de otro modo, entre los daños posibles que puede acarrear la falta de prueba, cuál de los dos posibles (condena del culpable o absolución del inocente) debe ser incondicionalmente evitado. 


\section{REFERENCIAS}

ARENS, Dogmatik und Praxis der Schädensschätzung, ZZP, 88; (con LÜKE) “Zivilprozessrecht”, München, 1992.

ARMENTA DEU, T., Lecciones de Derecho procesal civil, 4a ed. Marcial Pons, 2009.

BUJOSA VADELL, L., La protección jurisdiccional de los intereses de grupo, J.M. Bosch ed. S.A, Barcelona, 1995.

CASTRO ARGÜELLES, M.A. y ÁlVAREZ ALONSO, D., La igualdad efectiva de mujeres y hombres a partir de la Ley Orgánica 3/2007, de 22 de marzo, Thomson-Civitas, 2007, pp. 210ss

DE LA OLIVA SANTOS, Derecho procesal civil (El proceso de declaración), Ceura, $3^{a}$ ed. p. 428.

DEL POZO PÉREZ, M., ¿Es la tutela procesal de la mujer en la LO de Medidas de protección integral contra la violencia de género un anticipo de la ley de igualdad?, en AAVV ¿Igualdad para que?, Comares, 2007.

DIEZ-PICAZO- GIMENEZ, L. M., Sistema de Derechos fundamentales, Thomson.Civitas; Madrid, 2003, pp. 177-186.

GOLDSCHDMIDT, J., Der Prozess als Rechstlage, Berlin, 1925, pp. 335-362.

GUTIÉRREZ DE CABIEDES E HIDALGO DE CAVIEDES, P., La tutela jurisdiccional de los intereses supraindividuales, colectivos y difusos, Aranzadi, 1999, p. 199 (passim)

MARTÍNEZ DIZ, F., "Tutela judicial del derecho de igualdad entre mujeres y hombres y sus repercusiones procesales" en AAVV. Estudios interdisciplinares sobre igualdad y violencia de género, ed. Comares, Granada, 2008, pp. 291-295.

MONTERO AROCA, J., Derecho jurisdiccional (Proceso civil), 16 ed., p. 503.

MONTERO AROCA, J., La prueba en el proceso civil (5 a ed), ThomsonCivitas, 2007, p. 118-142.

OROMI VALL-LLOVERA, S., El ejercicio de la acción popular, Marcial Pons, 2003, passim.

CASTRO ARGÜELLES, M.A. y ÁLVAREZ ALONSO, D. La igualdad efectiva de mujeres y hombres a partir de la Ley Orgánica 3/2007, de 22 de marzo, Thomson-Civitas, 2007, pp. 210 y ss

ROSEMBERG, Die Beweislast. Auf die Grundlage des bürgerlichen Gesetzsbuch und der Zivilprozessordnung, 5a ed, Munich, 1965. 
SERRA DOMINGUEZ, M., "Contribución al estudio de la prueba" y "Reflexiones sobre una reciente concepción probatoria" en Estudios de Derecho Procesal, Barcelona, 1969. 